\title{
Modeling grain orientation of DP600 steel by Nd:YAG laser
}

\author{
Shibo Liu ${ }^{1,2, a}$, Afia Kouadri-Henni ${ }^{1,2}$ and Adinel Gavrus ${ }^{1,2}$ \\ ${ }^{1}$ Université Européenne de Bretagne, France \\ ${ }^{2}$ INSA-LGCGM-EA 3913, 20 avenue des Buttes de Coësmes, 35708, Rennes, France
}

\begin{abstract}
A FE-CA (Finite Element-Cellular Automaton) model is built to simulate the microstructure evaluation during laser welding of DP600 high strength steel. A moving conical heat source is performed in ABAQUS to achieve temperature field during welding. A linear interpolation method is used to transfer node temperature of ABAQUS to cell temperature of Cellular Automaton. With the consideration of temperature and solute concentration, the solidification of DP600 after weld is simulated. The established FE-CA model can simulate 2D equiaxed and column dendrite grain growth. The competitive growth between different dendrite arms is presented. The weld microstructure simulation result shows good agreement with experiment results.
\end{abstract}

\section{Introduction}

To relieve energy crisis and environment problems, high strength material is applied in automotive industries in order to reduce the car weight [1]. As a type of AHSS (advanced high-strength steel), DP steel is a low carbon steel which contains $3-30 \%$ hard martensite phase in a soft ferrite matrix [2]. The hard phase martensite contributes to the high strength while soft ferrite helps to improve ductility $[3,4]$, which make the steel a good combination of adequate formability and high strength. Compared with traditional high-strength low-alloy (HSLA) steels, DP steel has no yield point elongation and a higher strain-hardening rate [5]. The high strainhardening rate enhance the absorption of energy when deformation is happened, which helps decrease of damage in car collision [6].

Laser welding process efficiently integrates DP600 in the automobile industry. By employing appropriate welding parameters, the technique produces a strong weld joint altering the crystallographic texture. As the texture is the cause of anisotropy in rolled plates [7-8], the anisotropy may be changed by laser welding process. Arminjon [9] relates macroscopic anisotropy parameters using texture coefficients in one of mathematical models, where an appropriate grain orientation is an important parameter to calculate anisotropic property. Usually, to know experimentally the grain orientation of a material requires high price, either with advanced equipment or with tedious work. The aim to obtain the grain orientation by simulation, the Finite Element Method combined with Cellular Automaton Model (FE-CA) can be a successful way to simulate a $2 \mathrm{D}$ weld microstructure during solidifications.

A welding heat source plays an important role for FEM simulation of temperature distribution history

\footnotetext{
${ }^{\mathrm{a}}$ Corresponding author: shibo.liu@insa-rennes.fr
}

during solidification. Rosenthal [10] developed Point and Line Heat Source Models for moving heat resource to analyze weld thermal field history which has been popular in 1930s. Later, a Disc Model Heat Source Model with a Gaussian distribution of flux deposited on the surface of the plate was proposed by Pavelic et al. [11] and combined with FEM by Krutz et al. [12] and Friedman [13]. The model achieves more realistic temperature distribution than those calculated by Rosenthal model. Since the Disc Model is not suitable for high energy density welding such as laser welding, a Hemispherical Power Density Distribution volume source model was proposed by Paley et al. [14] and finally developed into Double Ellipsoid Three-Dimensional Heat Source Model [15]. After the popular double ellipsoid model, a Three-Dimensional Conical Heat Source seems to be more suitable for deep penetration welding [16]. In this paper, a Conical Heat Source is applied and a interpolation method is used to transfer temperature field from FEM to Cellular Automaton model.

Cellular Automaton (CA) was invented in late 1940s by Stanislaw Ulam and John von Neumann. After dozens of years' development, the CA method began to model grain structure formation in solidification by M.Rappaz and Ch.A. Gandin [17]. Six years later, Nastac [18] proposed a comprehensive CA model for simulating dendritic crystals growth during the solidification of binary alloys, in which work mathematical description, solution methodology and program algorithm are depicted in detail. In 2003, Wang et al. [19] successfully simulates equiaxed and columnar dendritic grains in 3D. In 2007, Y.H. Wei et al. [20] first attempt CA model on 2D simulation of welding solidification. Contributed to by many works [21-24], CA method has become a powerful tool in simulating microstructure evolution of welding solidification process. 


\section{Simulation}

The grain orientation analysis is sequentially coupled as a thermal-microstructure analysis. The simulation model consists in two parts:

1. Thermal analysis part:

- Heat source, heat transfer and boundary condition of radiation, convection and conduction are considered to analysis the thermal data of the model.

- The calculated thermal data is stored in a data file which is prepared for CA analysis.

2. Microstructure analysis part:

- An interpolation method for welding is proposed to import the thermal data of ABAQUS analysis model to the CA model.

- With the consideration of cell temperature, undercooling degree, nuclei density, solute concentration at the interfaces and between cells, dendrite tip curvature, growth velocity, and time increment, the condition of grain growth is simulated.

\subsection{ABAQUS temperature model}

\subsubsection{Dimensions}

The dimension of thermal analysis model of a lap-joint weld is presented in the Figure 1. The $0.1 \mathrm{~mm}$ gap is used to improve the weld quality. The zoomed zone of A-A part is shown together with the width of weld line equal to $1.2 \mathrm{~mm}$.
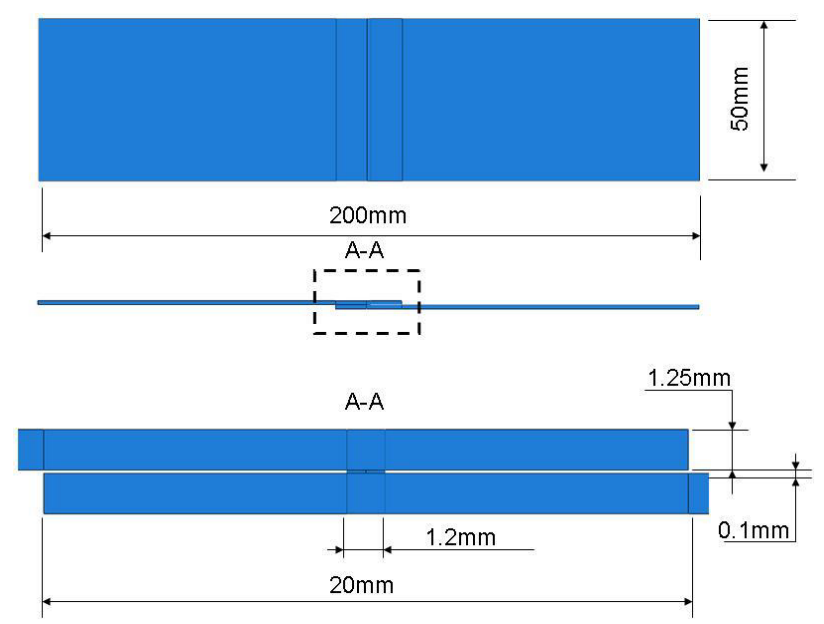

Figure 1. The dimension of welding simulation model

\subsubsection{Conical heat source}

In the case of deep penetration welding simulation, conical heat source with a Gaussian distribution is used as a suitable heat source model [16]:

$$
\mathrm{Q}_{\mathrm{v}}(r, z)=\frac{9 \eta \mathrm{Pe}^{3}}{\pi\left(\mathrm{e}^{3}-1\right)} \times \frac{\mathrm{e}^{-\frac{3 r^{2}}{r_{c}^{2}}}}{\left(\mathrm{z}_{\mathrm{e}}-\mathrm{z}_{\mathrm{i}}\right)\left(\mathrm{r}_{\mathrm{e}}^{2}+\mathrm{r}_{\mathrm{e}} \mathrm{r}_{\mathrm{i}}+\mathrm{r}_{\mathrm{i}}^{2}\right)}
$$

where $r_{c}$ is

$$
r_{c}=\mathrm{r}_{\mathrm{i}}+\frac{\left(\mathrm{r}_{\mathrm{e}}-\mathrm{r}_{\mathrm{i}}\right)\left(z-\mathrm{z}_{\mathrm{i}}\right)}{\mathrm{z}_{\mathrm{e}}-\mathrm{z}_{\mathrm{i}}}
$$

Table 1. Parameters of heat source.

\begin{tabular}{|c|c|c|}
\hline Symbol & Meaning & Magnitude \\
\hline $\mathrm{Q}_{\mathrm{v}}(\mathrm{r}, \mathrm{z})$ & total volumetric heat flux & $\mathrm{W} \cdot \mathrm{m}^{-3}$ \\
\hline $\mathrm{r}_{\mathrm{e}}$ & superior radius & $0.8 \mathrm{~mm}$ \\
\hline $\mathrm{r}_{\mathrm{i}}$ & inferior radius & $0.35 \mathrm{~mm}$ \\
\hline $\mathrm{r}_{\mathrm{c}}$ & variational radius & $r_{i} \leqslant r_{c} \leqslant r_{e}$ \\
\hline $\mathrm{Z}_{\mathrm{e}}$ & top surface position & $0.26 \mathrm{~mm}$ \\
\hline $\mathrm{Z}_{\mathrm{i}}$ & bottom surface position & $0 \mathrm{~mm}$ \\
\hline $\mathrm{P}$ & laser power & $4 \mathrm{KW}$ \\
\hline$\eta$ & laser absorption efficieny & $42 \%$ \\
\hline $\mathrm{V}$ & welding speed & $3 \mathrm{~m} / \mathrm{min}$ \\
\hline
\end{tabular}

\subsubsection{Heat transfer and boundary conditions}

The equation of heat transfer is governed by energy equilibrium balance:

$$
\rho \frac{d H}{d t}-\operatorname{div}(\lambda \operatorname{grad} T)-Q=0
$$

The convection limits condition on the surrounding surface can be written in the following form:

$$
\lambda(T) \operatorname{grad} T\left(x_{i}, t\right)_{\text {surface }}+h\left(T\left(x_{i}, t\right)-T_{0}\right)=0
$$

The radiation limits condition on the weld pool surface is written by

$$
\lambda(T) \operatorname{grad} T\left(x_{i}, t\right)_{\text {surface }}+\varepsilon \sigma\left(T\left(x_{i}, t\right)^{4}-T_{\propto}^{4}\right)=0
$$

In Equation 3, 4 and 5, $\rho$ is the density, $\mathrm{H}$ the enthalpy, $\mathrm{h}$ the convection coefficient, $\lambda$ the thermal conductivity, $\mathrm{t}$ the time, $\mathrm{T}$ the temperature, $\mathrm{Q}$ the internal heat, $\varepsilon$ the emissivity with a value of $0.25, \sigma$ the Stefan Boltzman with value $5.6704 \times 10-8 \mathrm{~W} /(\mathrm{m} \cdot \mathrm{K} 4)$. The surrounding temperature is supposed to be $25^{\circ} \mathrm{C}$.

\subsubsection{Material parameters}

Table 2 shows that the conductivity of DP600 material is temperature dependent.

Table 3 is presented the temperature dependent density of DP600.

In Table 4, the specific heat of dual phase material is defined to change with temperature. 
Table 2. Conductivity of model.

\begin{tabular}{|c|c|}
\hline Conductivity $\left(\mathbf{W} /\left(\mathbf{m}^{\circ}{ }^{\circ} \mathbf{C}\right)\right)$ & Temperature $\left({ }^{\circ} \mathrm{C}\right)$ \\
\hline 34.8 & 25 \\
\hline 35 & 200 \\
\hline 35 & 254 \\
\hline 21.4 & 1100 \\
\hline 25.5 & 1200 \\
\hline 60 & 1300 \\
\hline
\end{tabular}

Table 3. Density of model

\begin{tabular}{|c|c|}
\hline Mass density $\rho\left(\mathrm{Kg} / \mathrm{m}^{3}\right)$ & Temperature $\left({ }^{\circ} \mathrm{C}\right)$ \\
\hline 7594 & 0 \\
\hline 7300 & 1000 \\
\hline 7210 & 1200 \\
\hline 7200 & 1500 \\
\hline
\end{tabular}

Table 4. Specific heat of model

\begin{tabular}{|c|c|}
\hline Specific heat $\mathbf{c}\left(\mathbf{J} /\left(\mathbf{K g} \cdot{ }^{\circ} \mathrm{C}\right)\right)$ & Temperature $\left({ }^{\circ} \mathrm{C}\right)$ \\
\hline 520 & 0 \\
\hline 550 & 200 \\
\hline 600 & 400 \\
\hline 748 & 600 \\
\hline 690 & 800 \\
\hline 520 & 1100 \\
\hline 610 & 1200 \\
\hline 620 & 1500 \\
\hline
\end{tabular}

\subsection{Cellular Automaton microstructure model}

\subsubsection{Computation procedure}

The program procedure of weld solidification simulation is proposed with a CA computation method in a $2 \mathrm{D}$ mathematical model. The concentration of all cells are supposed to be the same at beginning of the procedure.

1. Temperature data is read from a 3D FEM ABAQUS Simulation and imported into a scanned 2D CA model.

2. The state of all cells, according to each cell temperature, are determined to be liquid, growing or solid.

3. If all cell temperatures is above melting temperature, time is increased, and the procedure returns to step 1. If not, nucleation and growth of liquid cells is computed.

4. For the growing cell, solid fraction, dendrite tip curvature, mesh anisotropy and concentration is computed.

5. Solute diffusion between cells is computed.

6. Crowing velocity (of solid/liquid interface moving) of growing cell is computed.

7. Time increment is computed.

8. Directions of cells are displayed using different colors.

9. If all the cell is solid, data is saved and computation stop. If not, the procedure return to step 1.

\subsubsection{Interpolation of Cell Temperature}

As is seen in Figure 2, the temperature history data, $T_{a}$, $\mathrm{T}_{\mathrm{b}}, \mathrm{T}_{\mathrm{c}}$ and $\mathrm{T}_{\mathrm{d}}$, are obtained from ABAQUS heat model and transferred to $2 \mathrm{D}$ Cellular Automaton by procedure interpolation on indirect method. The ABCD zone is meshed by $m \times n$ cells, and each cell is displayed by a pixel.

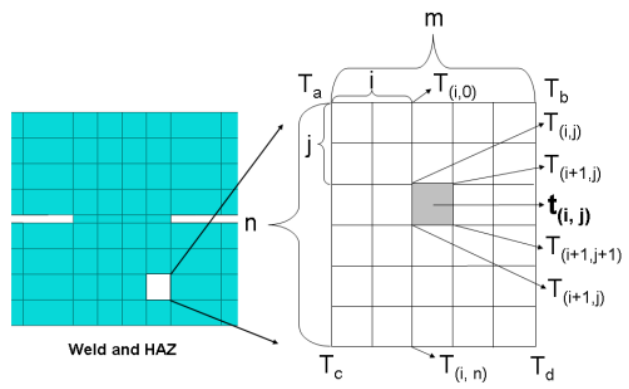

Figure 2. The schema of procedure linear interpolation method

First, the node temperature at the edge $\mathrm{T}_{(\mathrm{i}, 0)}$ and $\mathrm{T}_{(\mathrm{i}, \mathrm{n})}$ are interpolated. Second, node temperature $\mathrm{T}_{(\mathrm{i}, \mathrm{j})}$ is calculated. Finally, the cell temperature $t_{(i, j)}$ is estimated as a mean value of the four node temperature values:

$$
\begin{aligned}
T_{(i, 0)} & =\frac{i}{\mathrm{~m}}\left(T_{b}-T_{a}\right)+T_{a}=\frac{i}{\mathrm{~m}} T_{b}+\frac{(\mathrm{m}-i)}{\mathrm{m}} T_{a} \\
T_{(i, n)} & =\frac{i}{\mathrm{~m}}\left(T_{d}-T_{c}\right)+T_{c}=\frac{i}{\mathrm{~m}} T_{d}+\frac{(\mathrm{m}-i)}{\mathrm{m}} T_{c} \\
T_{(i, j)} & =\frac{j}{\mathrm{n}}\left(T_{(i, \mathrm{n})}-T_{(i, 0)}\right)+T_{(i, 0)} \\
& =\frac{1}{\mathrm{~m} \cdot \mathrm{n}}\left[(\mathrm{m}-i)(\mathrm{n}-j) \cdot T_{a}+i \cdot(\mathrm{n}-j) \cdot T_{b}\right. \\
& \left.+(\mathrm{m}-i) \cdot j \cdot T_{c}+i \cdot j \cdot T_{d}\right] \\
t_{(i, j)} & =\frac{1}{4}\left[T_{(i, j)}+T_{(i+1, j)}+T_{(i, j+1)}+T_{(i+1, j+1)}\right]
\end{aligned}
$$

\subsubsection{Nucleation}

According to the kinematic model described by Thevoz et al. [25], the nucleation density increases as undercooling increases. Because the undercooling of edge is bigger 
than that of bulk, the nucleation density of the edge is different from that of the bulk:

The edge of the weld pool ("e" stands for edge) [17] follows the kinematic equation:

$$
\delta n_{e}=\int_{\Delta \mathrm{T}}^{\Delta \mathrm{T}+\delta(\Delta \mathrm{T})} \frac{\mathrm{n}_{\mathrm{e}, \max }}{\sqrt{2 \pi} \Delta \mathrm{T}_{\mathrm{e}, \sigma}}\left(1-f_{e, s}\right) e^{-\frac{1}{2}\left(\frac{x-\Delta \mathrm{T}_{\mathrm{e}, \max }}{\Delta \mathrm{T}_{\sigma}}\right)^{2}} \mathrm{~d} x(10)
$$

The bulk of weld pool ("b" stands for bulk) is governed by:

$$
\delta \mathrm{n}_{\mathrm{b}}=\int_{\Delta \mathrm{T}}^{\Delta \mathrm{T}+\delta(\Delta \mathrm{T})} \frac{\mathrm{n}_{\mathrm{b}, \max }}{\sqrt{2 \pi} \Delta \mathrm{T}_{\mathrm{b}, \sigma}}\left(1-f_{b, s}\right) \mathrm{e}^{-\frac{1}{2}\left(\frac{x-\Delta \mathrm{T}_{\mathrm{b}, \max }}{\Delta \mathrm{T}_{\sigma}}\right)^{2}} \mathrm{~d} x(11)
$$

In the above formula, $\Delta \mathrm{T}$ is the whole undercooling of the bulk or edge i.e. $\Delta \mathrm{T}=\mathrm{T}_{\text {liq }}-\mathrm{T}_{\text {cell }}$. $\mathrm{T}_{\text {liq }}$ is the liquidus temperature according to phase diagram. $\mathrm{n}_{\mathrm{e}}$ is the nucleation density of the edge of weld pool. $n_{b}$ is the nucleation density of the bulk of weld pool. $\mathrm{n}_{\mathrm{e}, \max }$ and $\mathrm{n}_{\mathrm{b}, \max }$ are the maximum nucleation density for edge and bulk respectively. $\Delta \mathrm{T}_{\sigma}$ is the standard deviation of the degree of undercooling. $\Delta \mathrm{T}_{\mathrm{e}, \max }$ and $\Delta \mathrm{T}_{\mathrm{b}, \max }$ is the maximum degree of undercooling for edge and bulk respectively. $f_{e, s}$ and $f_{b, s}$ are fractions of solid already formed at the edge and the bulk. The increase of nucleation density, $\delta \mathrm{n}_{\mathrm{e}}$ or $\delta \mathrm{n}_{\mathrm{b}}$, multiplied by the edge cell number $(\mathrm{Ne})$ or the bulk number $(\mathrm{Nb})$, results to the number of cells nucleated at step $n$.

The nucleation position is chosen randomly among all remaining liquid cells. The nucleation probabilities [17] of the edge and bulk $\left(\mathrm{dp}_{\mathrm{e}}\right.$ and $\left.d \mathrm{p}_{\mathrm{b}}\right)$ during each time step are given by

$$
d p_{e}=\frac{\delta N_{e}}{\mathrm{~N}_{\text {edge }}}
$$

And

$$
d p_{b}=\frac{\delta N_{b}}{\mathrm{~N}_{\text {bulk }}}
$$

where $\mathrm{N}_{\text {edge }}$ and $\mathrm{N}_{\text {bulk }}$ are the cell number of the edge and the bulk of weld pool, respectively. During nucleation, each liquid cell is scanned and a random number, Rand, is assigned $(0 \leq \operatorname{Rand} \leq 1)$. The nucleation of a "liquid" cell will occur only if Rand $\leq d p_{e}$ or Rand $\leq d p_{b}$.

\subsubsection{Solid fraction}

The solid fraction of growing cells can be determined by [18]

$$
\delta f s=\frac{\delta t}{\mathrm{a}}\left(V_{x}+V_{y}-V_{x} V_{y} \frac{\delta t}{\mathrm{a}}\right)
$$

Here " $a$ " is the mesh size, $V_{x}$ is the maximum growth velocity of growing cell and $\delta$ t is the increment of time. If $f \mathrm{~s} \geq 1$, the cell state is changed from growing to solid and states of neighbor cells are changed from liquid to growing according to the limited angles method [21] to keep the growth angle. The limited angles method are presented in Figure 3. With many cells to stand for one cell, the growth direction can be fixed. The growth direction will always be kept in any circumstances.

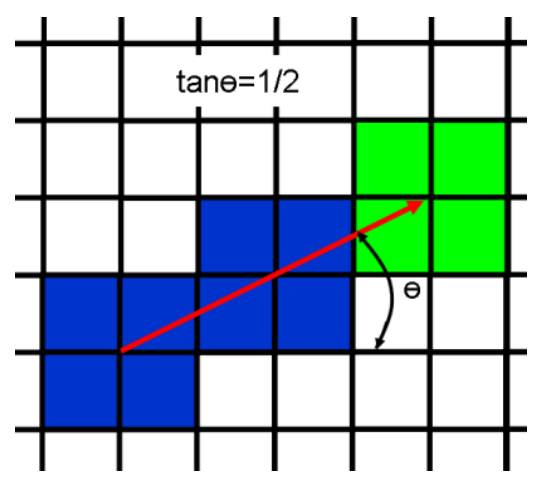

Figure 3. The growth direction with limit angle method

\subsubsection{Interface Curvature}

The solid/liquid interface curvature $\mathrm{K}$ for a cell is given by [18]:

$$
K=\frac{1}{\mathrm{a}}\left(1-2 \frac{f_{S}+\sum_{k=1}^{N} f_{S}(k)}{\mathrm{N}+1}\right)
$$

In the equation (15), a is the mesh size, fs is the solid fraction, $\mathrm{N}$ stands for the number of neighbor cells. The result of the curvature calculation range from $-1 /$ a to 0 for concave interface and from 0 to $1 /$ a for convex interface. With increment of $\mathrm{m}$ and $\mathrm{n}$ in Figure 2, the value of a decrease and can be very small.

\subsubsection{Interface Concentration}

For growing cell, the interface temperature $\left(\mathrm{T}^{*}\right)$ is given by [26]:

$$
T^{*}=\mathrm{T}_{\mathrm{L}}^{\mathrm{EQ}}+\left(C_{L}^{*}-\mathrm{C}_{0}\right) \mathrm{m}_{\mathrm{L}}-\Gamma K f(\varphi, \theta)-\frac{v}{\mu_{k}}
$$

where $T_{L}{ }^{E Q}$ is the equilibrium liquidus temperature and $\mathrm{mL}$ is the liquidus slope of phase diagram, $\Gamma$ is the Gibbs-Thomson coefficient and $f(\varphi, \theta)$ is a coefficient used to account the growth anisotropy. In laser welding process, the high velocity of grain growth induced by high temperature gradient is considered in terms of kinetic undercooling, where the interface temperature is affected by $\mathrm{v} / \mu_{\mathrm{k}}$. Here $\mathrm{v}$ is the growth velocity of solidliquid interface and $\mu_{\mathrm{k}}$ is the dynamic coefficient of grain growth.

For growing cell, the interface solute concentration $\mathrm{C}_{\mathrm{L}}^{*}$ can be calculated from Equation 16 :

$$
C_{L}^{*}=\mathrm{C}_{0}+\frac{T^{*}-\mathrm{T}_{\mathrm{L}}^{\mathrm{EQ}}+\Gamma \overline{\mathrm{k}} f(\varphi, \theta)+\frac{v}{\mu_{\mathrm{k}}}}{\mathrm{m}_{\mathrm{L}}}
$$

The solute concentration gradient $\mathrm{G}_{\mathrm{C}}$ in growing cell can be estimated: 


$$
G_{C}=\frac{C_{L}^{*}-C_{L}}{\left(1-f_{S}\right) \Delta \mathrm{x} / 2}
$$

where $\Delta \mathrm{x}$ is the mesh size in the $\mathrm{x}$ direction. Solute concentration in liquid cell is calculated from Equation 18:

$$
C_{L}=C_{L}^{*}-\frac{1-f_{S}}{2} \Delta \mathrm{x} G_{C}
$$

\subsubsection{Surface tension anisotropy}

The anisotropy of surface tension is estimated [18]:

$$
f(\varphi, \theta)=1+\delta \cos [4(\varphi-\theta)]
$$

Here, $\delta=0.04, \theta$ is the angle between growth direction and $+\mathrm{x}$ direction, and $\varphi$ is computed from the formula:

$$
\varphi=\operatorname{arcos}\left(\frac{V_{x}}{\left[V_{x}^{2}+V_{y}^{2}\right]^{1 / 2}}\right)
$$

\subsubsection{Diffusion Equation}

Starting from 3D cells, Figure 4 illustrates the diffusion of $2 \mathrm{D}$ cells. For the left cell, the upper part is viewed as solid and the lower as liquid. For the right cell, the front part is viewed as liquid and the back as solid.

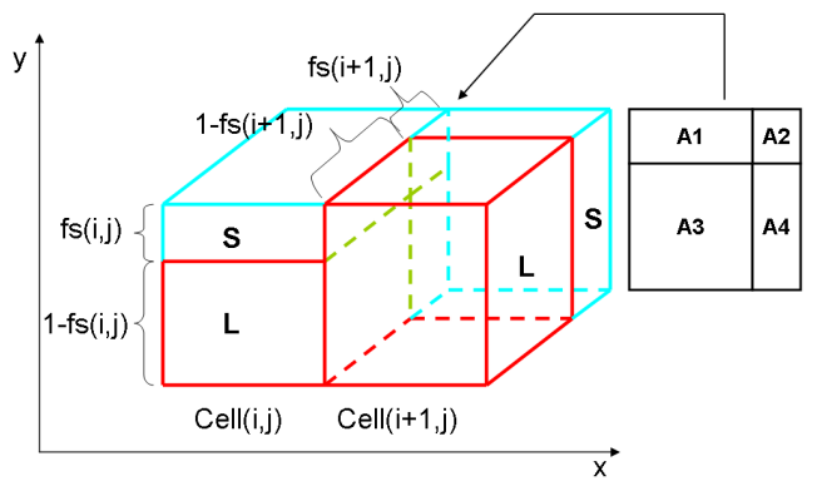

Figure 4. Schematic diagram of diffusion between CA cell

Using Fick's second law along the $\mathrm{x}$ direction, it is obtained:

$$
\frac{\partial C(x, t)}{\partial t}=-\frac{\partial J}{\partial x}
$$

where $\mathrm{C}$ is the concentration, $\mathrm{t}$ the time, and $\mathrm{J}$ the solute flux. The total contact area is A. A1 and A4 are contact region between liquid and solid. A2 is solid contact region. A3 is liquid contact region. The analyses have following expressions:

$$
A 1=f s(i, j) \cdot[1-f s(i+1, j)] \cdot \mathrm{A}
$$

$$
\begin{aligned}
& A 2=f_{S}(i, j) \cdot f_{S}(i+1, j) \cdot \mathrm{A} \\
& A 3=\left[1-f_{S}(i, j)\right] \cdot\left[1-f_{S}(i+1, j)\right] \cdot \mathrm{A} \\
& A 4=f_{S}(i+1, j) \cdot\left[1-f_{S}(i, j)\right] \cdot \mathrm{A}
\end{aligned}
$$

Every contact part is added together and finally the solute concentration has the following kinematic equation:

$$
\begin{aligned}
& \frac{\partial C(x, t)}{\partial t}=\mathrm{d}_{\mathrm{s}} \cdot \frac{C_{S}(i+1, j)-C_{S}(i, j)}{a^{2}} \cdot f_{S}(i, j) \cdot f_{S}(i+1, j) \\
& +\sqrt{\mathrm{d}_{1} \cdot \mathrm{d}_{\mathrm{s}}} \cdot \frac{C_{S}(i+1, j)-C_{L}(i, j)}{a^{2}} \cdot\left[1-f_{S}(i, j)\right] \cdot f_{S}(i+1, j) \\
& +\sqrt{\mathrm{d}_{1} \cdot \mathrm{d}_{\mathrm{s}}} \frac{C_{L}(i+1, j)-C_{S}(i, j)}{a^{2}} \cdot f_{S}(i, j) \cdot\left[1-f_{S}(i+1, j)\right] \\
& +\mathrm{d}_{1} \frac{C_{L}(i+1, j)-C_{L}(i, j)}{a^{2}} \cdot\left[1-f_{S}(i, j)\right] \cdot\left[1-f_{S}(i+1, j)\right]
\end{aligned}
$$

$d_{1}$ is diffusion coefficient of liquid and $d_{s}$ is diffusion coefficient of solid. $\mathrm{C}_{\mathrm{L}}$ and $\mathrm{C}_{\mathrm{S}}$ are solute concentration of liquid and solid respectively. $(i, j)$ refers to the position of the $i$ column and $j$ row. $f_{s}$ are solid fraction of cell.

\subsubsection{Growth Velocity of the Interface}

According to growth velocity expression by Nastic [18] in $\mathrm{x}$-direction(y-direction is similar):

$$
\begin{aligned}
V_{x}(i, j)= & \frac{\mathrm{d}_{1}}{\mathrm{a}(1-\mathrm{k})}\left[\left(1-\frac{C_{L}(i-1, j)}{C_{L}^{*}(i, j)}\right) f_{L}(i-1, j)\right. \\
& \left.+\left(1-\frac{C_{L}(i+1, j)}{C_{L}^{*}(i, j)}\right) f_{L}(i+1, j)\right] \\
& +\frac{\mathrm{kd}_{\mathrm{s}}}{\mathrm{a}(1-\mathrm{k})}\left[\left(1-\frac{C_{S}(i-1, j)}{k C_{L}^{*}(i, j)}\right) f_{S}(i-1, j)\right. \\
& \left.+\left(1-\frac{C_{S}(i+1, j)}{k C_{L}^{*}(i, j)}\right) f_{S}(i+1, j)\right]
\end{aligned}
$$

$\mathrm{k}$ is partition coefficient.

\subsubsection{Time step}

The time step is computed as [18]:

$$
\delta t=\frac{1}{5} \min \left(\frac{\mathrm{a}}{V_{\max }}, \frac{\mathrm{a}^{2}}{\mathrm{~d}_{1}}, \frac{\mathrm{a}^{2}}{\mathrm{~d}_{\mathrm{s}}}\right)
$$

Here, a is the mesh size, Vmax is the maximum growth velocity of growing cell.

\subsubsection{Parameters of the proposed $2 D C A$ model}

Table 5 presents the parameters of the proposed CA model. 
Table 5. Parameters of CA model.

\begin{tabular}{|c|c|c|}
\hline Symbol & Meaning & Magnitude \\
\hline $\mathrm{k}$ & Partition coefficient & 0.3 \\
\hline $\mathrm{d}_{\mathrm{l}}$ & Liquid diffusion coefficient & $3.0 \times 10^{-9} \mathrm{~m}^{2} \mathrm{~s}^{-1}$ \\
\hline $\mathrm{d}_{\mathrm{s}}$ & Solid diffusion coefficient & $3.0 \times 10^{-12} \mathrm{~m}^{2} \mathrm{~s}^{-1}$ \\
\hline $\mathrm{a}$ & Cell size & $10^{-7} \mathrm{~m}$ \\
\hline $\mathrm{T}_{\mathrm{L}}^{\mathrm{EQ}}$ & Liquidus temperature & $1530^{\circ} \mathrm{C}$ \\
\hline$\Gamma$ & Gibbs Thomson Coefficient & $1.9 \times 10^{-7} \mathrm{Km}$ \\
\hline $\mathrm{m}_{\mathrm{L}}$ & Liquidus slope & $-80{ }^{\circ} \mathrm{C} / \% \mathrm{Wt}$ \\
\hline$\Delta T_{e, \sigma}$ & Edge undercooling deviation & $20^{\circ} \mathrm{C}$ \\
\hline$\Delta T_{b, \sigma}$ & Bulk undercooling deviation & $50^{\circ} \mathrm{C}$ \\
\hline$\Delta T_{e, \max }$ & Edge mean undercooling & $20^{\circ} \mathrm{C}$ \\
\hline$\Delta T_{b, \max }$ & Bulk mean undercooling & $50^{\circ} \mathrm{C}$ \\
\hline
\end{tabular}

\section{Simulation results and discussion}

\subsection{Temperature evolution simulation}

According to the ABAQUS FEM, the temperature history are drawn in Figure 5. $T_{A}, T_{B}, T_{C}$ and $T_{D}$ are temperatures of four node A, B, C and D. The four nodes all experience a sudden increment and decrement of temperature. The maximum temperature of node $\mathrm{A}$ and $\mathrm{C}$ is higher than the liquidus temperature while node B and D not.

\subsection{Single nucleation supposing on isotropic temperature distribution}

As is shown in Figure 6, the simulation domain is made up of $300 \times 313$ cells with cell length of $1 \mu \mathrm{m}$. Under an supposing isotropic temperature environment and starting from a nucleation along the direction of $\theta=\arctan (1 / 2)$, an equiaxed dendrite growth is simulated. All cells follow the temperature of the node A. A small nuclei gradually grows to a big equiaxed dendrite which takes up the whole simulation zone. The interaction of secondary and tertiary arms can be clearly seen in Figure 6(c). The dendrite grows until meeting the entire simulation boundaries.

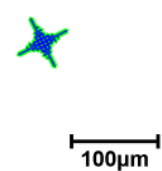

(a) 576 steps

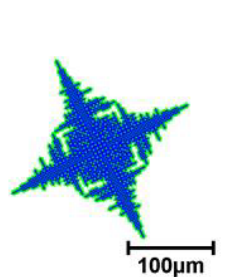

(b) 879 steps

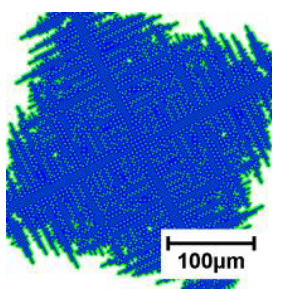

(c) 1399 steps
Figure 6. The growth of $2 \mathrm{D}$ equiaxed dendrite for three different time steps

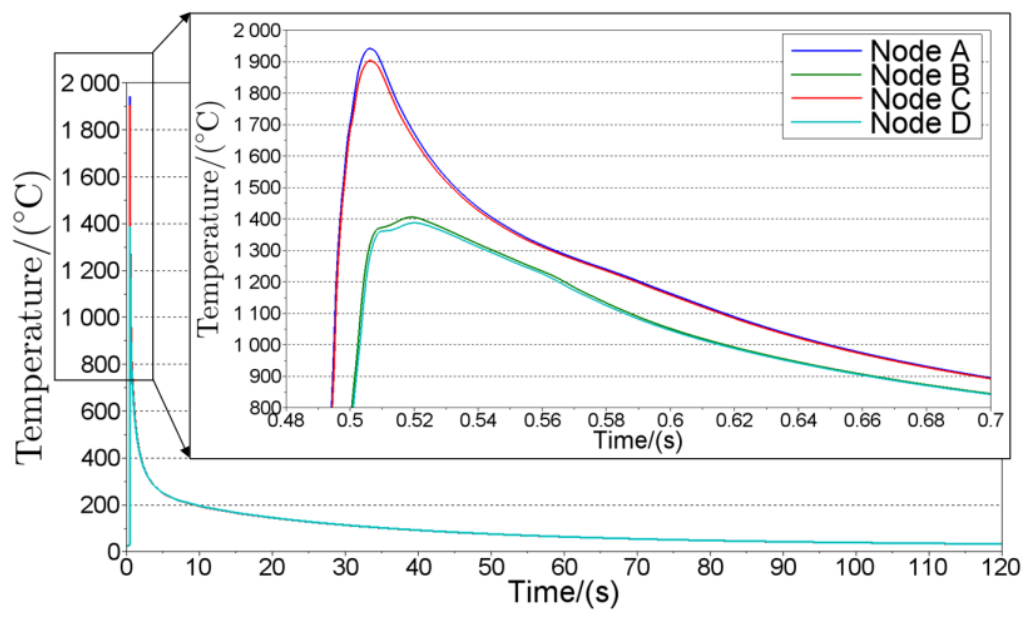

Figure 5. The temperature histories of four nodes corresponding to 2D CA domain.

\subsection{Edge dendrites growth supposing on isotropic temperature distribution}

As can be seen in the figure 7, the simulation domain is made up of $300 \times 313$ cells with cell length of $1 \mu \mathrm{m}$. Under an isotropic temperature environment and several small dendrite at edge with the same growth direction, the growth of columnar dendritic grains is simulated. Starting from small nucleus, 11 dendrites grow up to columnar dendrites at the same velocity towards the same direction. The columnar dendrites grow until they take up the whole simulation zone. The interaction of dendrite arms between different grains are presented in Figure 7(b) and 7(c). 


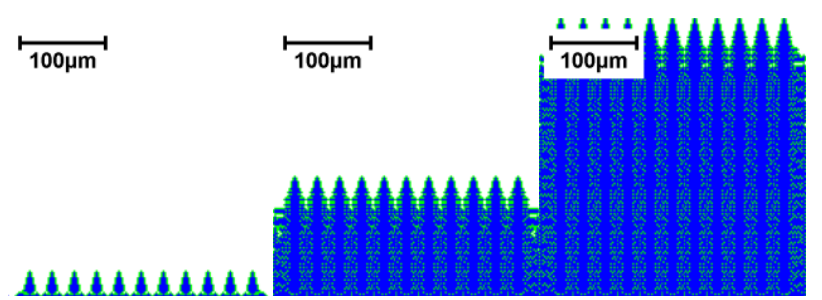
(a) 533 steps
(b) 971 steps
(c) 1697 steps

Figure 7. The growth of 2D columnar dendrites for three different time steps

\subsection{Microstructure simulation from the welding temperature distribution}

Unlike the isotropic temperature distribution assumptions used in section 3.2 and section 3.3, the temperature distribution used here are weld temperatures from FEM results in Figure 5. The simulation domain is made up of $900 \times 939$ cells with cell length of $0.33 \mu \mathrm{m}$. The interpolation of temperature is described in the previous section 2.2.2. The results are presented in Figure 8 .

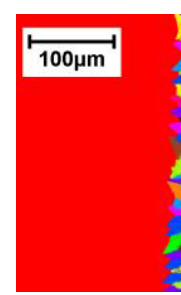

(a) Start

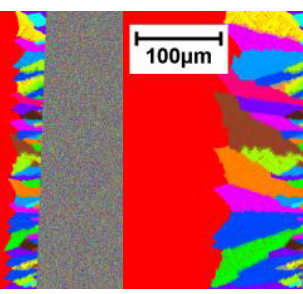

(b) Middle

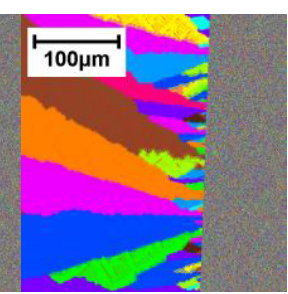

(c) End
Figure 8. Weld Microstructure Simulation for three different steps

So in figure 8(a), the beginning of the dendrite growth is presented. The left part with red colour stands for melting alloy, the middle part with different colours represent dendrites with different growth directions and the right part with random distributed colours are the never melt alloy. Nucleuses with random directions are randomly set at the edge. Figure 8(b) shows the competition of dendrite growth. Dendrites with the directions near to the preferential direction grow faster than those with directions far from the preferential. Growths of some dendrites are depressed by dendrites with faster growth directions. In figure 8(c), the final simulated microstructure of the $2 \mathrm{D} \mathrm{CA}$ model is presented. Only several dendrites with preferential growth directions grow up. The grains that go through melting and solidifying present an orientation towards the centre weld.

\subsection{Equiaxed dendrite}

Simulation results of $2 \mathrm{D}$ dendrite with different cell length are compared with the SEM observation of microstructure of DP600 weld in Figure 9(d) [27].

In microscope simulation, the equiaxed dendrite morphologies with different cell length are presented in Figure 9 (a), (b) and (c). All the simulation results provide similar morphology with dendrite in experiment observations. As the cell length of $2 \mathrm{D} \mathrm{CA}$ model decrease, the resolution of simulation increase and more detailed morphologic information can be achieved. If proper parameters are chosen, the cell length can be increased and the computation efficiency improved only with less precision for the CA model.

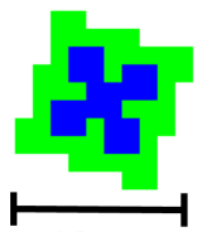

$10 \mu \mathrm{m}$

(a) Cell length $=1 \mu \mathrm{m}$

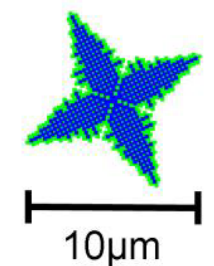

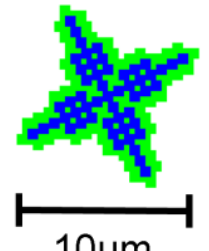

$10 \mu \mathrm{m}$ (b) Cell length $=0.294 \mu \mathrm{m}$

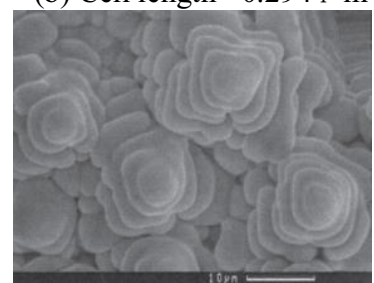

(c) Cell length $=0.067 \mu \mathrm{m}$ (d) DP600 weld microstructure [27] Figure 9. Dendrite morphology of 2D simulations and experimental SEM observation

\subsection{Microstructure of laser welding}

In Figure 10, a laser welding experiment is done according to the parameters described in Section 2.1. The corresponding simulation results are also presented in Figure 10 .

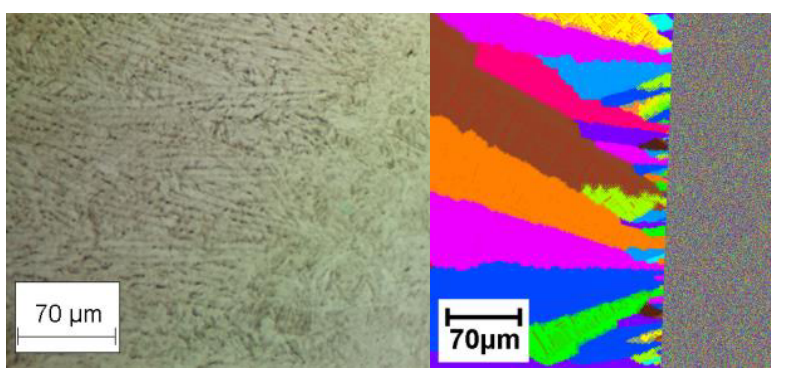

(a) simulation result (b) Optical observation

Figure 10. Microstructure of FZ and HAZ of DP600 weld

Using the temperature interpolation technique, a part of weld zone is simulated and compared with the optic observation. In a cross-section of weld simulation, orientations of dendrites are mainly from the edge to centre of the weld according well with experiment. At the beginning edge of molten pool, dendrites have random growth orientations. Under weld temperature distribution and with dendrites interaction, only grains with preferential orientations succeed to grow up. The final simulation result is similar to experiment observation except that the width of simulation dendrite still need to be improved.

\section{Conclusions}

A 2D Finite Element Cellular Automaton model for simulating microstructure evolution of DP600 by laser welding is developed. The chosen temperature 
interpolation method can successfully combine the simulation model of FEM with the microstructure model of Cellular Automaton. With the interpolation method, local microstructure of weld can be simulated based on the FEM temperature simulation results.

The CA model is capable to simulate equiaxed dendrite growth with one nucleation in the centre of simulation zone using the isotropic temperature distribution. The interaction of secondary and tertiary arms of equiaxed dendrites is also presented by the model. Simulation results are compared with experimental observation in the weld, and similar morphology is found.

The CA model is also able to simulate columnar dendrite growth with several nucleations at the edge of simulation zone with the isotropic temperature distribution. With interactions of dendritic arms between different dendrites, the simulated dendrites grow with the same velocity toward the same direction until the whole simulation zone is taken up.

The above FE-CA model coupling can predict the weld microstructure with random nucleations and weld temperature distribution. The results of simulation are compared with experimental observation and a good accordance is found. The FE-CA model can also successfully simulation local microstructure of weld based on the FEM temperature output data, which is important to further computation of grain orientation value. This work of $2 \mathrm{D}$ FE-CA coupling is just a beginning of a general model applied for laser welding simulation.

\section{Acknowledgement}

The work is financially supported by the China Scholarship Council and the laboratory LGCGM of INSA de Rennes.

\section{References}

1. G. Davies, Materials for automobile bodies (Elsevier,Butterworth-Heinemann, 2012)

2. M. Calcagnotto, Y. Adachi, D. Ponge, D. Raabe, Acta Materialia, 59, 658 (2011)

3. D. Chen, Z. Wang, X. Jiang, S. Ai, C. Shih, Mater. Sci. Eng., A, 108, 141 (1989)

4. S. Kuang, Y.1. Kang, H. Yu, R.d. Liu, Int J. Miner. Metall. Mater. 16, 159 (2009)

5. J. Fekete, A. Stibich, IBEC, 01, 3101 (2001)

6. O. Bouaziz, H. Zurob, M. Huang, Steel Res. Int. 84, 937 (2013)

7. B. Duggan, C.S. Lee, R. Smallman, Mater. Sci. Forum, 157, 1759 (1994)

8. B. Duggan, Y. Tse, H. Ning, M. Quadir, Mater. Sci. Forum, 408, 1151 (2002)

9. M. Arminjon, B. Bacroix, Acta Mechanica, 88, 219 (1991)

10. D. Rosenthal, ASME, (1946)

11. V. Pavelic, R. Tanbakuchi, O. Uyehara, P. Myers, Weld. J. 48, 295 (1969)

12. P. Tekriwal, J. Mazumder, Weld. J. 67, 150 (1988)
13. E. Friedman, J. Pres. Ves. Tech. 97, 206 (1975)

14. Z. Paley, P. Hibbert, Weld. J. 54, 385s (1975)

15. J. Goldak, A. Chakravarti, M. Bibby, Metall. Trans. B, 15, 299 (1984)

16. C. Wu, H. Wang, Y. Zhang, Weld. J. New. 85, 284 (2006)

17. M. Rappaz, C.A. Gandin, Acta Metall. Mater. 41, 345 (1993)

18. L. Nastac, Acta Mater. 47, 4253 (1999)

19. W. Wang, P.D. Lee, M. McLean, Acta Mater. 51, 2971 (2003)

20. Y.H. Wei, X.H. Zhan, Z.B. Dong, L. Yu, Sci. Tech.Weld. Join. 12, 138 (2007)

21. X. Zhan, Y.Wei, Z. Dong, J. Mater. Proce. Tech. 208, 1 (2008)

22. Y. Liu, Q. Xu, B. Liu, Tsinghua Sci. Tech. 11, 495 (2006)

23. M.F. Zhu, D.M. Stefanescu, Acta Mater. 55, 1741 (2007)

24. L. Beltran-Sanchez, D. Stefanescu, Metall. Mater. Trans. A, 34, 367 (2003)

25. P. Thevoz, J. Desbiolles, M. Rappaz, Metall. Trans. A 20, 311 (1989)

26. X.h. Zhan, Z.b. Dong, Y.h. Wei, Y. Wang, Chinese J. Nonferr. Metals. 19, 1431 (2009)

27. M. Marya, X.Q. Gayden, Welding Journal, 84, 172 (2005) 